\title{
Analysis of the Clinical Efficacy of Minocycline in the Treatment of Diabetic Retinopathy
}

\author{
LINA SONG, YUNJIU RONG, K. TANG, XUELING SONG, Z. LI, XUAN LI AND LEILEI YU* \\ Department of Ophthalmology, The $80^{\text {th }}$ Group Army Hospital of Chinese People's Liberation, Shandong 266071, China
}

Song et al.: Minocycline Efficacy in the Treatment of Diabetic Retinopathy

\begin{abstract}
Minocycline has been proven to reduce oxidative stress. This article further explores the safety and clinical efficacy of minocycline in the treatment of diabetic retinopathy. Selected 60 patients with diabetic retinopathy admitted to our hospital and divided them into two groups, observation group (30 cases) and control group (30 cases) randomly. Both groups received conventional treatment. Then treated control group with calcium dobesilate capsule and rosuvastatin calcium tablet. As well as the same drugs in control group, observation group received minocycline and the treatment period was $60 \mathrm{~d}$. Compared visual acuity score, diabetic retinopathy stage, retinal neovascularization fluorescein leakage area, incidence of complications and adverse drug reactions with both groups after treatment. The vision improvement of observation group was remarkably higher than control group $(\mathbf{p}<\mathbf{0 . 0 5})$; The incidence of retinopathy stage III in control group was $36.7 \%$, which was higher than $13.3 \%$ of observation group $(\mathbf{p}<\mathbf{0 . 0 5})$; After treatment, the retinal neovascularization fluorescein leakage area decreased to $241.3 \pm 12.44 \mathrm{~mm}^{2}$ and $249.3 \pm 16.12 \mathrm{~mm}^{2}$, respectively; The occurrence rate of complications in observation group was $30 \%$, while in control group was $56.7 \%$; The incidence of adverse drug reactions in both groups was basically similar $(p>0.05)$. Minocycline has a definite effect on patients with diabetic retinopathy. It can improve the vision of diabetic retinopathy patients; effectively reduce the stages of diabetic retinopathy, the leakage area of fluorescein in retinal neovascularization and the occurrence of related complications. It has no obvious adverse reactions and is worthy of clinical promotion.
\end{abstract}

Key words: Minocycline, diabetes, retinopathy, clinical efficacy

As the increasing prevalence rate of diabetes worldwide, Diabetic Retinopathy (DR) which mainly causes vision loss has become more and more important ${ }^{[1]}$. The main causes of vision loss include the occurrence of Diabetic Macular Edema (DME) and/or proliferative $\mathrm{DR}^{[2,3]}$. The treatment of DR mainly includes fundus laser photocoagulation and intraocular steroid injection ${ }^{[4]}$. Although these therapies are usually effective in reducing further vision loss, they can cause ocular side effects. In addition, such procedures are also invasive and destructive. Therefore, in order to improve and save vision in the early or even sub-clinical stage of the disease, it is necessary to explore effective treatment strategies $^{[5,6]}$. At present, the pathophysiological process leading to DME is not fully understood ${ }^{[7,8]}$. Its complex pathological mechanism goes beyond simple microvascular disease. More and more evidences indicate that inflammation is one type of key factors in DR development. The phenotype of leukocytes in DR structural and functional abnormalities play an important role ${ }^{[9]}$. Therefore, inhibition of inflammation can inhibit diabetes-induced angiopathy in DR diabetic

*Address for correspondence

E-mail: yll32298@163.com patients, thereby reducing vision loss in diabetic patients. Minocycline is a broad-spectrum tetracycline antibiotic with potent anti-inflammatory properties as well as its inhibition of microglia and macrophage activation. It has been proven to have function on reducing the occurrence of diabetes-induced inflammatory cytokines in cell cultures and animal model, decreasing cytotoxins release of activated microglia and remarkably decreasing apoptosis of retina, which are independent of its antibacterial properties $^{[10-12]}$. However, the current clinical efficacy of minocycline in DR treatment is still unclear. We processed this study to discuss and analyze the clinical effects of minocycline in the treatment of DR. We selected 60 hospitalized patients with DR in our hospital from February 2019 to March 2021 as research objects. According to whether minocycline was used or not, divided them into two groups, one is observation group (30 cases) and the other is control group (30 cases) randomly. The general information of both groups is shown in below Table 1. This study was approved by the medical ethics committee of our hospital. Inclusion 
criteria include patients who met DR diagnostic criteria proposed in "Guidelines for the Clinical Diagnosis and Treatment of Diabetic Retinopathy"; patients who were not allergic to the drugs used in this study; patients obtained informed consent for treatment. Exclusion criteria includes patients have serious disease and they are impossible to receive further effective treatment (e.g. eyes of central ischemia or macular scar); vision loss caused by other co-existive eye diseases; severe liver disease and renal dysfunction; critical patients with mental illness or cognitive dysfunction before admission; both groups received conventional treatment (e.g. controlling blood pressure, blood sugar and maintaining electrolyte balance). And then treated control group with rosuvastatin calcium tablets $(5 \mathrm{mg}$, orally, once a day) and calcium dobesilate capsules ( 0.5 $\mathrm{g}$, orally, three times a day); As well as receiving the same drugs as control group and observation group also received minocycline (100 mg; orally; every $12 \mathrm{~h}$ ). The treatment cycle is $60 \mathrm{~d}$. The change in visual acuity score relative to the baseline in the Early Treatment Diabetic Retinopathy Study (ETDRS) letters of the two groups after treatment ${ }^{[13]}$, is divided into the markedly effective, the effective and the ineffective. The markedly effective: After treatment, the visual acuity is improved more than 2 lines by visual inspection; Effective: The visual acuity is improved more than 1 line; Invalid: The visual acuity, microangioma and fundus oozing blood remain unchanged or even sharpened. Total clinical effective rate $=($ marked effective visual acuity improvement+effective visual acuity improvement)/ total number of cases $\times 100 \%$; stage of DR; fluorescein leakage area of retinal neovascularization; complications mainly include the retinal hemorrhage, increased intraocular pressure, endophthalmitis and macular edema, etc.; Adverse reactions mainly include allergic reactions, gastrointestinal reactions, liver and kidney damage, etc. We adopted Statistical Package for the Social Sciences (SPSS) 20.0 to process the data. Used $\mathrm{n} / \%$ to express count data and test by $\chi^{2}$. Use mean \pm standard deviation to indicate measurement data that is accord with normal distribution and homogeneity of variance, compared both groups by independent sample $t$ test. Use median and interquartile range to show data that did not accord with normal distribution, then adopted $\chi^{2}$ test. Use $(\overline{\mathrm{x}} \pm \mathrm{s})$ to express measurement data and compare by t-tests. $p<0.05$ indicates that the difference is statistically significant. Comparing both groups before treatment in terms of age, gender, visual acuity score and underlying diseases, there was no remarkable diversity $(p>0.05)$ and both groups were comparable. See the following Table 1. After both groups were treated, the total clinical effective rate of observation group was $66.7 \%$ and that of control group was $40 \%$, the difference had statistical significance $(p<0.05)$. The results of the efficacy evaluation of both groups are shown in Table 2. The incidence of retinopathy stage III in control group was $36.7 \%$, which was higher than $13.3 \%$ in observation group. But the incidence of stage I was lower than that of observation group. The divergence possessed statistical significance $(p<0.05)$ as shown in Table 3 . The fluorescein leakage area of retinal neovascularization in both group decreased to $241.3 \pm 12.44 \mathrm{~mm}^{2}$ and $249.3 \pm 16.12 \mathrm{~mm}^{2}$ respectively after treatment. The difference of both groups is of statistical significance, as shown in Table 4. Complications include retinal hemorrhage, increased intraocular pressure, endophthalmitis and macular edema. The total incidence of complications in control group was $56.7 \%$, which was remarkably higher than that of $30 \%$ in observation group and the divergence possessed statistical significance $(\mathrm{p}>0.05)$, as shown in Table 5 . It had no remarkable divergence in total adverse reaction rates such as allergic reactions, gastrointestinal reactions, liver and kidney damage in both groups $(p>0.05)$, as shown in Table 6. DR is one of the main complication of diabetes in working-age population, leading to decreased vision and even blindness ${ }^{[14]}$. The pathological features of DR include microaneurysms, exudates, hemorrhages and abnormal growth of blood vessels, which usually have two different stages, called Proliferative DR (PDR) and Non-Proliferative DR (NPDR $)^{[15,16]}$. NPDR occurs when the blood vessels in retina are damaged and start to leak fluid outside the blood vessels, causing the retina to become moist and swollen $^{[17]}$. In order to prevent vision loss, the current treatment mainly uses laser treatment and surgical removal of vitreous gel (vitrectomy) to improve vision $^{[18,19]}$. Although effective, the current laser and surgical treatment is still limited by high treatment burden, many ocular adverse reactions and unclear mechanism. Many studies have proved that the treatment strategy of inhibiting microglia may be a useful auxiliary method which widely targets DR chronic neuroinflammation, thereby helping the contraction of new blood vessels and improving vision $^{[20]}$. Minocycline, as a potential drug for microglia targeted therapy for DR, has a large amount of preclinical data to support its biological effects and potential efficacy and it has below advantages such as long use history, high bioavailability and known 
safety ${ }^{[21]}$. The results of this study show that after $60 \mathrm{~d}$ of treatment with minocycline, it helps to improve DR patients' vision, effectively reduce the stage of DR, significantly reduce the leakage area of fluorescein in retinal neovascularization and reduce the occurrence of related complications and there is no obvious adverse reaction. Our analysis suggests that this is related to the pathogenesis ofDR. The increased vascular permeability of DR patients may have relationship with existing activated retinal microglia which creates a large number of inflammatory mediators such as Tumor Necrosis Factor-Alpha (TNF- $\alpha$ ), interleukin-1 Beta $(\beta)$ and intercellular adhesion molecule 1, etc., thus inducing retinal leukocyte stasis and blood-retinal barrier destruction $^{[22]}$. It has been proved that minocycline can reduce microglia activation in the retina, so as to reduce the release and production of inflammatory cytokines and cytotoxins, thereby improving the anatomical effects of edema and vascular leakage. In addition, minocycline can also effectively reduce the upregulation of diabetes-induced caspase-3, which is apoptotic cell death's mediator in DR rodent models ${ }^{[23]}$. Of course, this study has some limitations. Since our research population is mainly for Chinese people, we need to be vigilant about the interpretation of this result to other populations; Secondly, our research sample size is too small and it is not ruled out that some errors may be caused to the research results. Minocycline has a definite effect on patients with DR, can improve the vision of patients with $\mathrm{DR}$, effectively reduce the stages of DR, the leakage area of fluorescein in retinal neovascularization and related occurrences and there is no obvious adverse reaction.

TABLE 1: COMPARISON OF GENERAL INFORMATION OF BOTH GROUPS

\begin{tabular}{lcccc}
\hline & $\begin{array}{c}\text { Observation group } \\
(\mathbf{n}=30)\end{array}$ & Control group $(\mathrm{n}=30)$ & $\mathrm{t} / \chi^{2}$ & $\mathrm{p}$ \\
\hline Age & $49.6 \pm 8.70$ & $48.9 \pm 8.75$ & 0.21 & 0.82 \\
Female & $16(53.3 \%)$ & $17(56.7 \%)$ & 0.07 & 0.79 \\
Underlying diseases & & & & \\
Hypertension & $19(63.3 \%)$ & $18(60.0 \%)$ & 0.07 & 0.79 \\
Coronary heart disease & $17(56.7 \%)$ & $18(60.0 \%)$ & 0.08 & 0.81 \\
Other & $2(6.7 \%)$ & $3(30.0 \%)$ & 0.22 & 0.64 \\
Visual acuity score & $0.23 \pm 0.04$ & $0.25 \pm 0.05$ & -1.71 & 0.09 \\
\hline
\end{tabular}

TABLE 2: COMPARISON OF THE EFFICACY OF VISION IMPROVEMENT ON BOTH GROUPS

\begin{tabular}{lcccc}
\hline & Markedly effective & Effective & Ineffective & Total effective rate \\
\hline $\begin{array}{l}\text { Observation group } \\
(\mathrm{n}=30)\end{array}$ & $10(33.3 \%)$ & $10(33.3 \%)$ & $10(33.3 \%)$ & $20(66.7 \%)$ \\
Control group $(\mathrm{n}=30)$ & $8(26.6 \%)$ & $4(13.3 \%)$ & $18(60 \%)$ & $12(40 \%)$ \\
$\chi^{2}$ & & & 4.29 & \\
$\mathrm{p}$ & & 0.04 & & \\
\hline
\end{tabular}

TABLE 3: COMPARISON OF THE STAGES OF DR ON BOTH GROUPS

\begin{tabular}{lccc}
\hline & Stage I & Stage II & Stage III \\
\hline Observation group $(\mathrm{n}=30)$ & $18(60.0 \%)$ & $8(26.7 \%)$ & $4(13.3 \%)$ \\
Control group $(\mathrm{n}=30)$ & $10(33.3 \%)$ & $9(30.0 \%)$ & $11(36.7 \%)$ \\
$\chi^{2}$ & 4.29 & 0.08 & 4.36 \\
$\mathrm{p}$ & 0.04 & 0.77 & 0.03 \\
\hline
\end{tabular}

TABLE 4: COMPARISION OF FLUORESCEIN LEAKAGE AREA OF RETINAL NEOVASCULARIZATION ON BOTH GROUPS BEFORE AND AFTER TREATMENT

\begin{tabular}{lccccc}
\hline & & $\begin{array}{c}\text { Observation group } \\
(\mathrm{n}=30)\end{array}$ & $\begin{array}{c}\text { Control group } \\
(\mathrm{n}=30)\end{array}$ & $\mathrm{t}$ & $\mathrm{p}$ \\
\hline $\begin{array}{l}\text { Retinal } \\
\text { neovascularization }\end{array}$ & Before treatment & $271.25 \pm 16.47$ & $272.26 \pm 15.52$ & -0.19 & 0.84 \\
$\begin{array}{l}\text { fluorescein leakage } \\
\text { area }\left(\mathrm{mm}^{2}\right)\end{array}$ & After treatment & $241.3 \pm 12.44$ & $249.3 \pm 16.12$ & -2.15 & 0.03 \\
\hline
\end{tabular}


TABLE 5: COMPARISON OF BOTH GROUPS COMPLICATIONS INCIDENCE AFTER TREATMENT

\begin{tabular}{|c|c|c|c|c|c|}
\hline & $\begin{array}{c}\text { Retinal } \\
\text { hemorrhage }\end{array}$ & $\begin{array}{l}\text { Increased } \\
\text { intraocular } \\
\text { pressure }\end{array}$ & Endophthalmitis & Macular edema & $\begin{array}{l}\text { Total incidence of } \\
\text { complications }\end{array}$ \\
\hline $\begin{array}{l}\text { Observation group } \\
(\mathrm{n}=30)\end{array}$ & 2 (6.7 \%) & $3(10.0 \%)$ & $1(3.3 \%)$ & $3(10.0 \%)$ & $9(30.0 \%)$ \\
\hline $\begin{array}{l}\text { Control group } \\
(n=30)\end{array}$ & $3(10.0 \%)$ & 5 (16.7 \%) & $3(10.0 \%)$ & $6(20.0 \%)$ & 17 (56.7 \%) \\
\hline$\chi^{2}$ & & & 4.34 & & \\
\hline $\mathrm{p}$ & & & 0.03 & & \\
\hline
\end{tabular}

TABLE 6: THE INCIDENCE OF ADVERSE REACTIONS IN BOTH GROUPS

\begin{tabular}{|c|c|c|c|c|c|}
\hline & Allergic reactions & $\begin{array}{c}\text { Gastrointestinal } \\
\text { reactions }\end{array}$ & Liver damage & Kidney damage & $\begin{array}{l}\text { Total incidence of } \\
\text { adverse reactions }\end{array}$ \\
\hline $\begin{array}{l}\text { Observation group } \\
(n=30)\end{array}$ & $3(10.0 \%)$ & $1(3.3 \%)$ & $2(6.6 \%)$ & $0(0.0 \%)$ & $6(20.0 \%)$ \\
\hline $\begin{array}{l}\text { Control group } \\
(n=30)\end{array}$ & $2(6.7 \%)$ & $1(3.3 \%)$ & $1(3.3 \%)$ & $0(0.0 \%)$ & $4(13.3 \%)$ \\
\hline$\chi^{2}$ & & & 0.48 & & \\
\hline $\mathrm{p}$ & & & 0.48 & & \\
\hline
\end{tabular}

\section{Conflict of interests:}

The authors declared no conflicts of interest.

\section{REFERENCES}

1. Cukras CA, Petrou P, Chew EY, Meyerle CB, Wong WT. Oral minocycline for the treatment of Diabetic Macular Edema (DME): Results of a phase I/II clinical study. Invest Ophthalmol Vis Sci 2012;53(7):3865-74.

2. Mohamed QA, Ross A, Chu CJ. Diabetic retinopathy (treatment). BMJ Clin Evid 2011;2011.

3. Yuan M. Early diagnosis and comprehensive prevention and treatment of diabetic retinopathy. Chin J Med 2018;53(4):35861.

4. Shao Y, Zhou Q. Interpretation of clinical guidelines for diabetic retinopathy of the American academy of ophthalmology. Recent Adv Ophthalmol 2019;39(6):501-6.

5. Dhamdhere KP, Bearse MA, Harrison W, Barez S, Schneck ME, Adams AJ. Associations between local retinal thickness and function in early diabetes. Invest Ophthalmol Vis Sci 2012;53(10):6122-8.

6. Fundus disease group of Ophthalmology Society of Chinese Medical Association. Guideline for clinical diagnosis and treatment of diabetic retinopathy in China. Chin J Ophthalmol 2014;50(11):851-65.

7. Xie Y, Huang M. Research progress on mechanism of minocycline on diabetic retinopathy. Recent Adv Ophthalmol 2016;36(12):1184-7.

8. Tian Q, Cao Q, Lu Y. Minocycline regulates MCPIP1/NLRP3 pathway and inhibits apoptosis in diabetic retinopathy. Chin J Mod Appl Pharm 2020;37(17):2081-5.

9. Zapadka TE, Lindstrom SI, Batoki JC, Lee CA, Taylor BE, Howell SJ, et al. Aryl hydrocarbon receptor agonist VAF347 impedes retinal pathogenesis in diabetic mice. Int J Mol Sci 2021;22(9):4335.
10. Pang Y. Study on the inhibitory effect of minocycline on retinopathy of diabetic rats. Sichuan Univ 2006.

11. Lian H, Ren B, Gao X. Effects of minocycline on apoptosis of retinal nerve cells of rats with diabetic retinopathy. Prog Mod Biomed 2011;11(13):2435-7.

12. Grotegut P, Perumal N, Kuehn S, Smit A, Dick HB, Grus FH, et al. Minocycline reduces inflammatory response and cell death in a S100B retina degeneration model. J Neuroinflammation 2020;17(1):1-23.

13. Narayanan D, Rodriguez J, Wallstrom G, Welch D, Chapin M, Arrigg $\mathrm{P}$, et al. An exploratory study to evaluate visual function endpoints in non-advanced age-related macular degeneration. BMC Ophthalmol 2020;20(1):1-3.

14. Liu X, Wang X, He Y. The research progress of risk factors and prevention in diabetic retinopathy. Recent Adv Ophthalmol 2018;38(7):687-91.

15. Wang Y, Chen S. Research progress on the pathogenesis, protection and prevention of nerve damage in diabetic retinopathy. Chin J Ocular Fundus Dis 2014;30(2):209-11.

16. Takayama K, Someya H, Yokoyama H, Takamura Y, Morioka $\mathrm{M}$, Sameshima S, et al. Risk factors of neovascular glaucoma after 25-gauge vitrectomy for proliferative diabetic retinopathy with vitreous hemorrhage: A retrospective multicenter study. Sci Rep 2019;9(1):1-6.

17. Amin J, Sharif M, Yasmin M. A review on recent developments for detection of diabetic retinopathy. Scientifica 2016;2016.

18. Vujosevic S, Martini F, Convento E, Longhin E, Kotsafti O, Parrozzani R, et al. Subthreshold laser therapy for diabetic macular edema: Metabolic and safety issues. Curr Med Chem 2013;20(26):3267-71.

19. Takayama K, Someya H, Yokoyama H, Kimura T, Takamura $\mathrm{Y}$, Morioka M, et al. Prognostic factors of revitrectomy for complications in eyes with proliferative diabetic retinopathy: A retrospective multicentre study. Acta Ophthalmol 2020;98(4):e434-9. 
20. Biswas S, Bachay G, Chu J, Hunter DD, Brunken WJ. Laminindependent interaction between astrocytes and microglia: A role in retinal angiogenesis. Am J Pathol 2017;187(9):2112-27.

21. Scholz R, Sobotka M, Caramoy A, Stempfl T, Moehle C, Langmann T. Minocycline counter-regulates pro-inflammatory microglia responses in the retina and protects from degeneration. J Neuroinflammation 2015;12(1):1-4.

22. Wang J, Li M, Song Z. Research progress on the mechanism and cell model of diabetic retinopathy. J Otolaryngol Ophthalmol Shandong Univ 2014:1-7.

23. Rzepka Z, Beberok A, Pawlik J, Wrześniok D. Cellular and molecular aspects of anti-melanoma effect of minocycline-A study of cytotoxicity and apoptosis on human melanotic melanoma cells. Int J Mol Sci 2020;21(18):6917.
This is an open access article distributed under the terms of the Creative Commons Attribution-NonCommercial-ShareAlike 3.0 License, which allows others to remix, tweak, and build upon the work non-commercially, as long as the author is credited and the new creations are licensed under the identical terms

This article was originally published in a special issue, "Novel Therapeutic Approaches in Biomedicine and Pharmaceutical

Sciences" Indian J Pharm Sci 2021:83(6) Spl Issue "231-235” 